to travel $100 \mathrm{~km}$ further could provide climate benefits, if this avoided contrail formation as a result.

Environ. Res. Lett. 9, 064021

(2014)

ZOOLOGY

\section{Wasps build charnel houses}

A newly described species of wasp protects its nest with the corpses of dead ants.

Michael Staab of the University of Freiburg in Germany and his colleagues placed artificial nests for solitary wasps in the Zhejiang region of China. Of the 829 nests they later collected, 73 had an outer chamber filled with dead ants, as well as several inner chambers containing a paralysed spider for each wasp larva to feed on. This new species (Deuteragenia ossarium sp. nov.) seemed less vulnerable to parasites than wasps using similar but ant-less nests. The authors suggest this 'bonehouse wasp' uses the ants as a nest-protection strategy. PLoS ONE 9, e101592 (2014)

\section{CHEMISTRY}

\section{Water-repellent chemical sponges}

Researchers in Japan have created sponge-like crystals that soak up gases and liquids, but repel water.

Compounds known as porous coordination polymers can store or separate different molecules from a mixture, and produce catalytic reactions within their pores. But the polymers often break down in water. Susumu Kitagawa and his colleagues at Kyoto University designed small organic molecules, which they combined to make a porous crystal. The material has a nanometre-scale corrugated outer surface, which repels water droplets but draws other liquids through it. A previous strategy to make porous crystals water-repellent has been to attach bulky molecules after the crystal is made, but this has the undesirable side effect of blocking the pores that gases and non-aqueous liquids are supposed to enter. Angew. Chem. Int. Edn http://doi. org/f2sr5g (2014)

\section{PLANETARY SCIENCE}

\section{Hit-and-run origin for Mercury}

Mercury may have formed as the result of one or more 'hitand-run' collisions between the many protoplanets in the early Solar System.

Mercury, the closest planet to the Sun, is unusual because its large metallic core lacks a massive rocky mantle like the ones that cover Earth, Venus and Mars. Erik Asphaug and Andreas Reufer at Arizona State University in Tempe modelled impacts between planetary embryos in the early Solar System. They show that Mercury may be a survivor of one or multiple early Solar System collisions with a larger planet that stripped off the mantle of the smaller body, leaving only the iron-rich core.

Although the chance of the smaller body surviving each such collision is unlikely, the authors show that if the planet did survive, it is statistically probable that it would have suffered multiple hit and runs.

Nature Geosci. http://dx.doi. org/10.1038/ngeo2189 (2014)

\section{METABOLISM \\ Obesity without diabetes}

A protein that breaks down iron compounds in the blood could be the key to why some people who are obese can maintain healthy metabolisms and do not develop diabetes.

Andrew Pospisilik of the Max Planck Institute of Immunobiology and Epigenetics in Freiburg, Germany, Harald Esterbauer

SOCIAL SELECTION Romianarical

Republished paper draws fire

Many scientists have denounced the republication of a retracted study by Gilles-Eric Séralini and colleagues that linked genetically modified maize (corn) to tumours in rats.

Kevin Folta, a horticultural scientist at the University of Florida in Gainesville, tweeted "Holy lumpy rats! Republished Seralini \#GMO paper had no scientific peer review before published in the new journal." In reply, Mary Mangan, an independent bioinformatics researcher based in Boston, Massachusetts, tweeted "So it was more like exhumed than republished".

Environ. Sci. Eur. 26, 14 (2014)

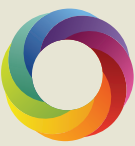

Based on data from altmetric.com. Altmetric is supported by Macmillan Science and Education, which owns Nature Publishing Group.

ONATURE.COM

For more on popular papers: go.nature.com/g5wwpj at the Medical University of Vienna and their colleagues examined liver and fat tissue from both 'healthy' obese people and obese people who were resistant to insulin. The authors found lower levels of a molecule called haem oxygenase-1 (HO-1) in the healthy individuals. Obese mice engineered to lack the gene responsible for $\mathrm{HO}-1$ production remained sensitive to insulin and had fewer metabolic problems than normal obese mice. HO- 1 may be involved in inflammation that leads to metabolic disease, and finding ways to inhibit it could lead to new therapies, the authors suggest.

Cell 158, 25-40 (2014)

\section{Bellows blow plant pollen}

Plants in Ecuador and Costa Rica have evolved a remarkable 'bellows' system for blowing pollen onto feeding birds.

Agnes Dellinger and Jürg Schönenberger at the University of Vienna and their colleagues found that the flowers of the tropical genus Axinaea contain stamens

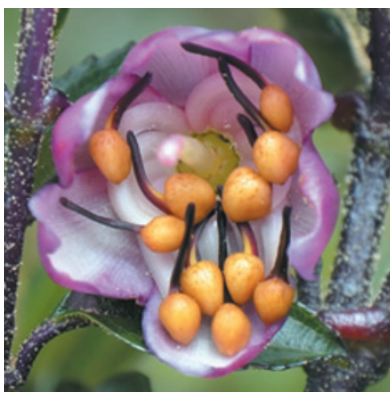

with bulbous appendages When these are grabbed and squeezed in the beaks of passerine birds, a blast of air from the cavity-filled appendages fires a jet of pollen onto the birds' heads and beaks.

The stamens provide a highly sugar-rich food for the birds, rather than the nectar or pollen reward that is more usually offered by flowers. The researchers did not observe insects foraging on the Axinaea flowers (pictured), but multiple bird species were seen feeding on them, suggesting that these stamens are a novel pollinator-activated pollen delivery system.

Curr. Biol. http://doi.org/thv (2014)

\section{NATURE.COM}

For the latest research published by Naturevisit:

www.nature.com/latestresearch 